\title{
ASO Author Reflections: Gastric Cancer Staging: More than Just TNM?
}

\author{
Jakub Chmelo, MUDr, MRCS, and Alexander W. Phillips, MD, MA, FRCSEd \\ Northern Oesophagogastric Unit, Newcastle upon Tyne, UK
}

\section{PAST}

Pre-operative clinical staging of gastric cancer patients is currently based on TNM classification. ${ }^{1}$ The disease stage may influence patient management and provide important prognostic information to help counsel patients. The importance of additional information from the cancer specimen regarding lymphatic, venous or perineural invasion in the context of neo-adjuvant chemotherapy for gastric adenocarcinoma remains unclear. These have been identified as important within other cancer groups but not necessarily incorporated into the staging of the disease. ${ }^{2}$ The question remains, are these factors associated with poorer outcomes in the post-neoadjuvant gastric cancer cohort? Past studies have evaluated their impact in a neoadjuvant naive group. ${ }^{3,4}$ Most importantly, could knowledge about these factors influence our decisionmaking about treatment strategies of this aggressive disease?

\section{PRESENT}

This study reveals additional prognostic factors for patients with gastric adenocarcinoma who were treated with neo-adjuvant chemotherapy and surgery. ${ }^{5}$ The presence of lymphatic, venous and perineural invasion are features of aggressive tumours. These histological findings in the resection sample may play a prognostic role. Further, they could potentially help stratify patients at higher risk of recurrence and aid the decision-making process with

(C) The Author(s) 2020

First Received: 22 March 2020; Published Online: 6 April 2020

A. W. Phillips, MD, MA, FRCSEd

e-mail: awphillips@doctors.net.uk regards to administration of adjuvant chemotherapy. This may be particularly useful for patients who are node negative. Knowledge about the presence of these factors preoperatively [endoscopic mucosal resection (EMR) or biopsy based] might also lead to different treatment strategies. This could be the case especially for patients who are staged as having node-negative disease, where an earlier 'T-stage' may preclude them from neoadjuvant treatment.

\section{FUTURE}

Future research studies assessing various adjuvant strategies in gastric cancer patients should incorporate information about these prognostic factors. Data need to be collected to establish their full prognostic significance. As a better understanding is developed, the prognostic significance of these histopathological factors may influence decision-making of multidisciplinary teams involved in looking after gastric cancer patients. Surgery and lymphadenectomy continue to be the key components for treating gastric cancer patients. However, the future lies in tailoring treatment specifically to patients and their tumour biology to minimise unnecessary interventions and their side-effects and ensure an optimum therapy.

OPEN ACCESS This article is licensed under a Creative Commons Attribution 4.0 International License, which permits use, sharing, adaptation, distribution and reproduction in any medium or format, as long as you give appropriate credit to the original author(s) and the source, provide a link to the Creative Commons licence, and indicate if changes were made. The images or other third party material in this article are included in the article's Creative Commons licence, unless indicated otherwise in a credit line to the material. If material is not included in the article's Creative Commons licence and your intended use is not permitted by statutory regulation or exceeds the permitted use, you will need to obtain permission directly from the copyright holder. To view a copy of this licence, visit http://creativecommons. org/licenses/by/4.0/. 


\section{REFERENCES}

1. Brierley JDGM, Wittekind C, Amin MB (eds). TNM classification of malignant tumours. 8th ed. New York: Wiley-Blackwell; 2016.

2. Lagarde SM, Phillips AW, Navidi M, Disep B, Immanuel A, Griffin SM. The presence of lymphovascular and perineural infiltration after neoadjuvant therapy and oesophagectomy identifies patients at high risk for recurrence. $B r \quad J$ Cancer. 2015;113(10):1427-33.

3. Deng J, You Q, Gao Y, Yu Q, Zhao P, Zheng Y, Fang W, Xu N, Teng L. Prognostic value of perineural invasion in gastric cancer: a systematic review and meta-analysis. PLOS ONE. 2014;9(2):e88907.
4. Li P, Ling YH, Zhu CM, Hu WM, Zhang XK, Luo RZ, He JH, Yun JP, Li YF, Cai MY. Vascular invasion as an independent predictor of poor prognosis in nonmetastatic gastric cancer after curative resection. Int J Clin Exp Pathol. 2015;8(4):3910-8.

5. Woodham BL, Chmelo J, Donohoe CL, Madhavan A, Phillips AW. The prognostic significance of lymphatic, venous and perineural invasion after neoadjuvant chemotherapy in patients with gastric adenocarcinoma. Ann Surg Oncol. 2020. https://doi. org/10.1245/s10434-020-08389-7.

Publisher's Note Springer Nature remains neutral with regard to jurisdictional claims in published maps and institutional affiliations. 